\title{
(Re) conhecendo suas casas: narrativas sobre a desospitalização de crianças com doenças de longa duração
}

\section{| ${ }^{1}$ Barbara da Silveira Madeira de Castro, ${ }^{2}$ Martha Christina Nunes Moreira I}

Resumo: Focalizamos as narrativas dos familiares de crianças com adoecimentos de longa duração sobre o processo de desospitalização por eles vivenciado, privilegiando espaços do cotidiano de duas famílias. As mulheres continuam sendo as principais cuidadoras das crianças, e se sentem sobrecarregadas, sem conseguir identificar apoios e redes de suporte. O processo de ida para casa é desafiador, exigindo para mães ressignificar suas vidas após um período de longa internação. As crianças passam a maior parte do tempo em casa. Outros espaços de acolhimento que estejam para além dos serviços de saúde ainda são muito escassos e pouco disponíveis. Mais que oferecer um "treinamento aos pais", é preciso trabalhar elementos de ordem emocional, vinculados aos sentimentos de segurança e insegurança, que podem vir a representar o diálogo hospital/ casa.

Palavras-chave: crianças; família; desospitalização; doenças crônicas; narrativa.

\author{
1 Instituto Nacional de Saúde \\ da Mulher, da Criança e \\ do Adolescente Fernandes \\ Figueira. Fundação Oswaldo \\ Cruz. Rio de Janeiro-RJ, Brasil \\ (barbarasmcastro@gmail.com). \\ ORCID: 0000-0003-3185-3703 \\ 2 Instituto Nacional de Saúde \\ da Mulher, da Criança e \\ do Adolescente Fernandes \\ Figueira. Fundação Oswaldo \\ Cruz. Rio de Janeiro-RJ, Brasil \\ (marthacnmoreira@gmail.com) \\ ORCID: 0000-0002-7199-3797
}

Recebido em: 28/02/2018 Revisado em: 08/06/2018 Aprovado em: 22/06/2018 


\section{Introdução}

A transição no perfil epidemiológico e demográfico brasileiro teve como um de seus desdobramentos o incremento nos índices de prevalência de doenças crônicas e degenerativas não somente na faixa etária de adultos, mas também de crianças e jovens (MOREIRA, GOLDANI, 2010). Na atenção neonatal, recém-nascidos anteriormente inviáveis passaram a ter uma maior sobrevida, e o número de crianças dependentes de tecnologia crescendo e se desenvolvendo aumentou (MOREIRA et al., 2016, 2017).

Ao se tratar das especificidades clínicas dessas crianças, podemos falar que vivem com condiçóes médicas complexas ou crônicas complexas de saúde (COHEN et al., 2011). Tal definição engloba uma vida mediada por malformaçóes associadas ou não a síndromes e deficiências variadas, cuja dependência de tecnologia e de equipes multiprofissionais refere uma complexidade de intervençôes que sustentam a vida, muitas vezes restringindo essas crianças a longos períodos em unidades de internação. A saúde e a qualidade de vida dessas crianças fora dos hospitais dependem da integração entre atençáo básica e os serviços de saúde da atenção terciária (MOREIRA et al., 2016). Outros lugares de cuidado são também fundamentais nesse processo de integração, como as unidades de reabilitação, a casa, a escola e os espaços comunitários (MOREIRA et al., 2014).

Mesmo reconhecendo que na literatura internacional o termo "Condiçóes crônicas complexas" (CCC) mais bem descreve a clínica da cronicidade em crianças, este não incorpora a experiência de adoecimento, em seus aspectos relacionais, intersubjetivos, que dialogam com outros padrōes de normalidade e adaptaçôes que essas crianças desenvolvem. A descrição das crianças a partir da sua clínica, orientada pela biomedicina, ajuda-nos a clarear questóes da ordem da mecânica, da fisiopatologia, da organização das dependências de tecnologias que as marcam e dimensionam suas necessidades de cuidado. Para a formulação de políticas públicas, poder utilizar um conceito que especifique uma clínica diferenciada é essencial para os avanços necessários na programação e planejamento em saúde, mas não é suficiente.

Urge dialogar tais referências com as memórias da experiência de vida e os arranjos cotidianos para enfrentar os desafios da desospitalização e o encontro com a casa. Privilegiamos o contexto narrativo da experiência com o termo "adoecimento de longa duração" (CANESQUI, 2013) para que, além das questôes clinicas e suas implicações mais diretas, possamos ouvir o sujeito e sua experiência. 
Esses adoecimentos levam a internaçóes prolongadas, podendo variar de meses até anos conforme aponta a literatura (NEWACHECK, KIM, 2005; MOURA et al., 2017; MOREIRA et al., 2017), e por isso a volta para casa é menos uma alta hospitalar, e mais um processo de desospitalização. Aqui definido como "uma operação normativa, de retirada do ambiente e de gerar outros locais de referência que incluem inúmeras negociaçôes simbólicas e geográficas" (MOREIRA et al., 2017, p. 6).

A viabilidade para sair do hospital não depende apenas da estabilização de seus quadros clínicos, mas de adaptaçôes na casa: obras de eletricidade, compra de refrigeração para o ambiente, colocação de pisos que facilitem a higiene, abertura de janelas, retirada de infiltraçôes e focos de mofo. As famílias a que nos referimos pertencem muitas vezes a extratos populacionais onde a pobreza as faz viver em locais que não estão adequados às necessidades especiais de saúde dos filhos e filhas. Aos poucos, o hospital e seus discursos de higiene e cuidados vão entrando na casa, que passa a ser até mesmo inspecionada antes de receber a criança e sua família novamente; assim esse espaço vai se reconfigurando para todos que ali moravam.

A mudança do hospital para casa supera uma simples mudança física, e se assume como um campo relacional, onde estão em diálogo significados, expectativas, investimentos. Pinto et al. (2010) ressaltam que as intervençôes de apoio e suporte devem ter início ainda na hospitalização, com vistas a melhorar o enfrentamento de permanência e alta da criança e da família.

Essa reflexão nos leva a reconhecer que para crianças com internaçóes prolongadas, em virtude de condiçôes crônicas complexas, e experienciando o adoecimento crônico, o processo de ida para casa revela mais que a mudança de um lugar de convivência institucional de caráter fechado - um hospital - para o ambiente privado da intimidade da casa. Conhecer melhor as inseguranças que essas transiçóes representam pode contribuir para um cuidado integral à saúde de crianças adoecidas cronicamente.

Neste artigo, focalizamos as narrativas dos familiares de crianças com adoecimentos de longa duração sobre seus processos de desospitalização, com o objetivo de explorar as referências de apoio que colaboraram para garantir o crescimento da criança no hospital e posteriormente em casa, e desvelar os desafios que isso representa na retomada e estabelecimento de novas rotinas, com as emoçôes que mediam esse processo. 


\section{Metodologia}

Na base do artigo reside uma pesquisa de mestrado aprovada pelo Comitê de Ética sob o número CAAE: 55816116.2.0000.5269. Privilegiando o método da narrativa, vinculamos um lugar estratégico às memórias (POLLAK, 1989), para a construção identitária da criança, e para a reconstrução identitária de seus cuidadores em situaçóes críticas de nascimento de um filho marcado pelas experiências de adoecimento e internação prolongada. Memórias essas que são transformadas ao serem contadas, acontecimentos que são narrados não como relatos factuais, mas como reconstrução de identidade. $\mathrm{O}$ acesso a essas memórias é o que abre a possibilidade de construção da narrativa considerada como produção de sentido, de criação de novas possibilidades. Assim, o que se deseja com o uso da narrativa enquanto método é ouvir não só o que a pessoa fala, mas como a pessoa fala sobre sua experiência, a maneira como ela apresenta o que narra, a ordem que escolhe para narrar os acontecimentos, tudo isso é caro para a análise das narrativas (HYDÉN, 1997).

Foram entrevistadas duas mães que tiveram seus filhos hospitalizados por 1 ano e 2 meses e 1 ano e 11 meses. Com a primeira delas, a entrevista foi feita no curso de reforço escolar que sua filha frequenta. Assim, a entrevista foi feita em duas etapas durante o tempo em que sua filha estava na aula, em torno de 1 hora e 30 minutos. Já com a segunda mãe, a entrevista foi feita em sua casa, ao longo de uma manhã, em que estavam presentes seu marido e dois de seus três filhos. Nos primeiros vinte minutos de entrevista, seu marido participou e pôde fazer uma breve narrativa sobre o processo de desospitalização por eles vivenciado. Ou seja, recuperando suas memórias sobre o tempo no hospital e a desospitalização, com a chegada em casa.

As entrevistas eram iniciadas com a seguinte pergunta: Como foi o processo de ida para casa? Partindo da ideia de que essa pergunta seria provocadora para o acesso às memórias das mulheres sobre o processo de adoecimento dos seus filhos, sobre quanto a experiência de ter um filho com uma doença de longa duraçâo mudou suas vidas e experiência.

As narrativas foram gravadas, transcritas, lidas pela pesquisadora e por sua orientadora, e a partir dessa leitura, a análise dos dados foi feita considerando as experiências relatadas, dialogando-as com os objetivos da pesquisa. Quais sejam: identificar as referências de apoio que contribuíram para garantir o crescimento da criança no hospital e posteriormente em casa, e desvelar os desafios que isso 
representa na retomada e estabelecimento de novas rotinas, e as emoçóes que mediam esse processo. Assim, alcançamos quatro núcleos comuns: (a) A casa e a rua: reconhecendo-se estrangeiro na sua própria casa; (b) As rupturas na vida das mães: as memórias das mulheres; (c) O lugar das crianças e como as mães as percebem; (d) Apoios e redes sociais.

Foram selecionadas famílias com crianças com condiçóes crônicas complexas reconhecidas como doenças de longa duração, que tivessem experienciado internaçóes de mais de 90 dias. As famílias que residiam em locais considerados de alto risco foram excluídas da pesquisa, pois a proposta era que as entrevistas pudessem ser feitas em espaços de vida cotidiana das crianças e suas famílias. Assim, locais tidos como de alto risco na cidade do Rio de Janeiro poderiam ser inacessíveis para a pesquisadora. A necessidade de preservaçáo da integridade física da pesquisadora não era somente um imperativo de segurança própria, ela foi reconhecida por outra mulher, que a princípio seria entrevistada e que indicou o momento de insegurança e violência a que estava exposta onde morava, manifestando que a entrada da pesquisadora ofereceria risco a ela própria, contraindicando sua visita a casa.

Com base no cumprimento dos requisitos da Resolução CNS no 466/12, todos os nomes são fictícios e as identidades não são reveladas.

\section{Resultados e Discussão}

Foram selecionadas inicialmente para a pesquisa quatro famílias, considerando os critérios de inclusão indicados. Como somente duas delas puderam ser acessadas em ambientes cotidianos de vida da criança - casa ou escola -, as outras duas, em virtude de problemas de risco pela violência no bairro e/ou por impossibilidade de marcação no ambiente cotidiano em função de uma segunda gravidez da mãe, não puderam ser entrevistadas. Assim, para o presente artigo trabalharemos com as narrativas de duas famílias cujos nomes de mães, pais e crianças foram alterados a fim de guardar anonimato.

A primeira família foi a de Helena e sua filha Júlia de 4 anos e 8 meses de idade. Helena tem 48 anos, é casada com o pai de Júlia há nove anos e é mãe de um rapaz de 21. Helena deu à luz Júlia e só pouco mais de um mês depois percebeu a coloração da pele de sua filha alterada, amarelada, e a levou ao hospital. Depois de um tempo internada em um hospital particular em sua cidade, Júlia foi transferida para um 
hospital público de referência no Rio de Janeiro, onde se diagnosticou que a icterícia fora causada por um processo inflamatório que gerou obstrução dos ductos biliares, condição chamada atresia de vias biliares. Júlia passou por algumas cirurgias para a reversão do quadro, mas como não surtiram o efeito esperado, foi indicado o transplante de fígado, em São Paulo. Foram quatro meses internada no Rio de Janeiro e mais dez meses (internada) em São Paulo até poder voltar para sua casa.

A segunda família foi a de Daniela e Pedro e Pedrinho de 4 anos e 11 meses de idade. Daniela foi encaminhada ao hospital de referência com doze semanas de gestação. Após um exame já ter detectado uma anomalia cardíaca, descobriu-se que Pedrinho tinha síndrome de Down, com seu quadro agravado por uma série de malformações e disfunções. Foram diversas intervençôes cirúrgicas e sessões de imunoglobulina até Pedrinho, após deixar de ser dependente de oxigênio, conseguir ir para casa, com 1 ano e 11 meses. Durante esse tempo, foi pedido na justiça que Pedrinho fosse para casa com home care, e esse pedido foi concedido pouco tempo depois de sua alta.

\section{A casa e a rua: reconhecendo-se estrangeiro na sua própria casa}

A desospitalização é uma conquista para pais e para os profissionais de saúde, mas essa ida para casa tem diversos significados e marca o começo de uma nova etapa para as famílias, com inseguranças e o desenvolvimento de expertise materna na identificação de sinais de risco para a saúde já tão instável dos filhos, em um papel de cuidadoras em tempo integral. Na entrevista, Helena pôde colocar com clareza essa questão:

(...) é na volta pra casa que começa. Enquanto você tá no hospital você está lidando com a doença, mas tem várias pessoas pra te socorrer, primeiro passo: você fica aguardando a alta mesmo sabendo quando ela vai ser, aí quando vem a alta você pergunta: e agora? Como é que vai ser? Uma criança que está melhor, mas ainda tem uma doença, a insegurança é muito grande, será que eu dou conta? [...] Mas qual era o objetivo? A melhora da Júlia, entâo eu me bloqueei. Bloqueei algumas coisas, sentimentos em prol da Júlia (Helena).

A ida para casa pode inaugurar uma tensão entre saber x não saber, insegurança $\mathrm{x}$ bloqueio, desestabilizando aprendizados anteriores, feitos sob apoio e orientação profissional. Estar no hospital é estar sob responsabilidade institucional. A trajetória de uma família que passa por um longo período de internação e tem um filho 
com uma doença crônica é reorganizada, e além da necessidade que é imposta externamente de se ter um ambiente suficientemente seguro e adequado para as crianças, há uma necessidade de as mães se readaptarem e refletirem sobre o lugar onde habitam e o reflexo que isso traz para suas vidas:

Aí a gente foi pra casa e eu não quero ninguém na minha casa, porque eu era muito neurótica com esse negócio de imunidade. Eu não tocava ninguém nos corredores do hospital, eu não abraçava, entấo assim, eu tinha muito medo de levar alguma coisa pro meu filho, então eu fiquei neurótica, lavava mão toda hora, minha mão era grossa de tanto álcool, sabonete que eu passava, e era aquilo, não quero ninguém na minha casa (Daniela).

A intimidade e a privacidade como qualidades de um ambiente como o da casa não são garantidas em um hospital. E para essas famílias levar o filho para casa pode significar fazer da casa uma extensão do hospital, no caso acima promovendo um ambiente asséptico, quase táo artificial como uma instituição, em um modelo idealizado, que nem mesmo o hospital realiza, mas parece cultivar. Ou seja, a casa se tornaria um híbrido de espaço privado e íntimo, mas com a assepsia necessária à manutenção de uma criança com um quadro complexo de saúde.

Diante dessa apreensão, vale assumir a casa como uma categoria sociológica (DAMATTA, 1985), compreendendo-a em diálogo com "a rua”. E esses dois espaços configuram-se como domínios culturais, suportes para símbolos, promotores de interpretaçóes, que os fazem transcender sua presença como meros espaços físicos, despertando emoções e reaçôes. A casa e sua representação enquanto espaço seguro, do que há de mais íntimo, só pode ser assim entendida quando contrastada com o mundo exterior, a rua. A casa pode ser tanto um espaço físico, como o hospital pode ser interpretado como casa pelas crianças longamente internadas, pela segurança que pode garantir no monitoramento clínico, na responsabilidade que assume. Ao retornar para casa depois de uma longa internação, os sentimentos gerados podem ser de insegurança e estranhamento, contrastando com a imagem tradicional de segurança e privacidade que a casa pode representar. Retornar para casa com uma criança que vive adoecida cronicamente revela-se como um desafio permanente.

Em alguns momentos, o espaço do hospital se torna o lugar de segurança, onde seus filhos estão sendo cuidados todo o tempo e amparados por equipamentos que podem ser usados quando e se necessário. Já a casa, lugar para onde se almeja voltar, precisa ser (re)conhecida como o lugar seguro e esse reconhecimento faz parte de um processo muitas vezes tão doloroso quanto prazeroso para essas famílias. 
Quando uma criança que ficou um longo período internada vai para casa, as maiores preocupações são "treinar" as mães, que são em maior parte as cuidadoras (MOREIRA et al., 2017; GAVAZZA et al., 2008.), garantir que elas saibam agir em casa mantendo a rotina de cuidados a seus filhos. Por mais que a equipe se preocupe em estar presente e em poder ajudar sempre, pouco espaço é aberto para que essas mulheres possam sair do lugar de "mães ideais" (PAEZ, MOREIRA, 2016) e falar de seus medos e preocupaçóes. A presença da criança com doença crônica em casa representa para a família que já tinha estabelecidas suas tarefas próprias, o aprendizado de novos papéis, outras formas de dividir as obrigaçóes e se relacionar internamente e com o meio ambiente (MARCON et al., 2007).

A ida para casa, então - após uma longa internação onde seus filhos estavam em um espaço visto por elas como controlado -, pode representar um enorme risco para a saúde de seus filhos e um aumento de responsabilidade para as famílias. A casa é reconstruída na tensão permanente segurança $\mathrm{x}$ insegurança, risco x vigilância, controle x segredo. Assim, elas buscam fazer do espaço de casa um espaço igualmente controlado, restringindo a proximidade das visitas, restringindo os lugares que seus filhos possam ir. As mães passam a ter a sensação de que se "algo acontecer" serão elas as responsabilizadas e criam estratégias para lidar com isso. Entretanto, viver sob essa responsabilidade traz consequências na vida dessas famílias, em especial dessas mulheres.

\section{Rupturas na vida das mães: as memórias das mulheres}

É esperado das mães nas sociedades ocidentais que elas se dediquem inteiramente a seus filhos, conseguindo trabalhar, cuidar de si e de sua casa, mas que possam dedicar grande parte do seu tempo a seus filhos (LUPTON, 2013). Ser uma boa mãe está intimamente relacionado, nos dias de hoje, a ser uma boa cidadã:

Aquela Helena eu não tenho mais [falando sobre si ], eu sou vigilante, alerta o tempo todo. Se eu for a um lugar, não me permito mais bebida, não que eu bebesse, mas se eu quiser beber uma taça de vinho alguma coisa que as pessoas até relaxam naquela conversa, eu não me permito isso, porque eu tenho que estar vigiando. Eu não posso sair do meu controle, pra eu olhar, pra eu observar se ela tem ferida no corpo, se ela tá apresentando alguma coisa, o canto da boca que às vezes abre, eu já tenho que passar pomada. Eu não quero que as coisas vão adiante (....) O meu banho é rápido, eu não sei ficar debaixo do chuveiro, tomar aquele banho relaxante. Sábado é um dia que a minha mãe vai de manhã e brinca com ela, é um dia que tomo o banho relaxada um pouquinho mais, mas mesmo assim meu ouvido fica atento pra ver se está acontecendo alguma coisa. Eu relaxar não 
consigo mais, minha voz mudou, meu tom de voz mudou, não é mais calmo, é forte, meu jeito de ser mudou todinho (Helena).

Recai sobre as mães uma autovigilância, incrementando responsabilizações pela saúde de seus filhos. Ter um filho com uma condição crônica pode representar um desafio na tarefa de ser uma "boa máe". Esses cuidados tornam-se um imperativo para que seu filho possa estar em casa, com o apagamento da função paterna, que também pode e deve cuidar. Essas mulheres ganham a responsabilidade de gerir suas casas para que essas sejam lugares apropriados onde seus filhos possam ficar. É possível observar que o que as mães apreendem é a ideia de que elas são capazes de controlar tudo, que as escolhas que elas fazem diariamente serão os principais determinantes para o bem-estar de seus filhos. E essas escolhas têm consequências diretas em suas vidas.

Smith (2013) aponta para o impacto na vida da mãe que passa a exercer o papel de principal cuidadora de um filho adoecido longamente. Segundo Alves e Bueno (2018), a mãe, muitas vezes no papel de cuidadora principal, negligencia a própria saúde. Ao tentar lidar e se adaptar às novas configuraçôes colocadas pela condição de seus filhos, o foco são as necessidades da criança, como aponta Helena. Essa tentativa de responder a todas as demandas que são identificadas como urgentes pode gerar um intenso desgaste físico e também emocional.

Mães de crianças com condiçôes crônicas se reconhecem sabendo mais que qualquer um, incluindo o pai da criança, como lidar com ela, como administrar a medicação e monitorá-la (LUPTON, 2013). Elas ressaltam o quanto conhecem seus filhos e como detalhes que só elas são capazes de perceber podem mostrar que algo não vai bem. Afirmam que quase instintivamente são capazes de saber como seus filhos estão. Moreira, Cunha e Mello (2016) destacam ainda que a presença dessas crianças vivendo com condiçôes complexas e raras produz "novas" mães que aprendem a falar de seus filhos incorporando avaliações técnicas, dominando conhecimentos sobre tecnologias, parâmetros e sinais que podem indicar risco de morte para seus filhos. Elas dominam diagnósticos e manejam com isso as relaçôes de poder com os profissionais de referência, autorizando-se a questionar e serem protagonistas desse processo de cuidar.

Esse modelo, das mães como principais responsáveis pela saúde de seus filhos, amparado no discurso médico do início do século XX, está intimamente ligado 
ao ideal de promoção da saúde de que cada um deve cuidar de sua própria saúde. Nessa lógica, ter acesso às informaçóes é o suficiente para que cada sujeito faça suas escolhas, sendo responsabilizado caso adoeça. Afinal, não fez boas escolhas, não se exercitou suficientemente, não se alimentou da maneira correta, não fez exames periodicamente.

Quanto às mães encorajadas a agir racionalmente, Lupton (2013) as denomina "enterpreneurial citizens", evocando um mandato social que atribui à mãe, não cuidar, mas gerir a saúde de seus filhos. Quando esse filho possui uma doença crônica, a gestáo do cuidado, o agir racionalmente tornam-se ainda mais imperativos. Cabe às mães manter o tratamento de seus filhos em casa, agir rápida e racionalmente caso algo aconteça, fazer tudo o que está e não está ao seu alcance para que sejam consideradas boas mães pelos profissionais de saúde. Não é raro ouvir julgamentos a respeito das mães, não das famílias, não do pai, mas das mães que não administraram o remédio na hora ou dosagem correta, que não obrigam seus filhos a comer, ou a fazer fisioterapia etc.

Ao assumirem o papel de principais cuidadoras de seus filhos (DINIZ, 2007; SMITH, 2013; ALVES, BUENO, 2018), as mães reorganizam suas vidas em torno desse cuidado, responsabilizam-se por tudo o que acontece na vida dos mesmos, sentindo-se culpadas pelo o que não acontece da maneira idealizada. Segundo Pinto et al. (2010), a preocupação com a recuperação do filho, com a reação do marido/ companheiro, amigos e família extensa opera como fator estressor. Incluindo a preocupação com orçamento familiar interferindo no funcionamento da família, considerando o aumento de gastos com transporte, medicaçóes e perda de dias de trabalho, principalmente da mãe.

Essas mães, além do cansaço físico e mental, experienciam limitaçóes nas suas interaçôes sociais. Sair de casa por si só já constitui um desafio que se torna um limitador, fazendo com que fiquem cada vez mais isoladas. O que se percebe, como Lupton (2013) aponta, é que pouco se fala das questóes emocionais e de sentimentos como raiva, impaciência e frustração das mães no cuidado de seus filhos. Assumir esses sentimentos pode evocar culpa, mas é preciso refletir que isso não exclui sentir amor por eles.

O espaço de pesquisa foi reconhecido como uma oportunidade de poder falar sobre as questóes pessoais, sobre as frustrações, sobre não ser uma mãe ou uma mulher perfeita: 


\begin{abstract}
Comecei a ficar depressiva, não queria mais sair de casa, não queria mais fazer as coisas. Aí eu fui procurar acompanhamento psicológico particular pelo memorial. Aí o médico falou que eu tava tendo uma crise de ansiedade [...] Aí eu comecei a tomar fluoxetina, aí me sentia um pouco mais calma, mas ainda não satisfeita com a minha vida, muito infeliz, muito chorosa e comecei a brigar com Pedro. Só que Pedro é um homem muito paciente, ele procurava não discutir comigo, falava quer chorar, chora, quer gritar, grita. E não tinha com quem me abrir, só com meu marido, só com meu marido (Daniela).
\end{abstract}

As duas mães eram consideradas pela equipe do hospital "mães ideais" no cuidado de seus filhos, as duas com ensino superior, organizadas, acompanhadas de seus maridos. Essa imagem construída pela equipe do hospital reforça a imagem de mães ideais, modelos. Os espaços para a desconstrução dessa imagem e desse imperativo vão se reduzindo, o que leva essas mães a se sentirem ainda mais isoladas e mais responsabilizadas para o sustentarem, o que costuma ter um custo emocional alto em suas vidas.

\title{
O lugar das crianças e como as mães as percebem
}

Considerando as experiências que as famílias, principalmente as mães, de crianças com doenças de longa duração vivenciam e a importância dessa questão, uma metassíntese identificou quatro temas recorrentes (NELSON, 2002): 1 - Se tornar mãe de uma criança com deficiência; 2 - A negociação de um outro tipo de cuidado materno; 3 - Lidar com uma vida nova que será diferente do que era até então e, por último, 4 - O processo de aceitação e negação.

O processo de desospitalização provoca emoçóes cercadas de estranhamentos para as mulheres: na ida para casa, o cuidado com a criança ganha outro sentido, com sentimentos de angústia e preocupaçáo muitas vezes escondidos. Esse processo é antecedido do aprendizado sobre o cuidado com seu filho adoecido cronicamente e deve ser considerado para podermos compreender o lugar ocupado por essa criança.

Se tornar mãe de uma criança adoecida cronicamente exige uma reconstrução da própria ideia de se tornar mãe. As mães relatam o quanto os primeiros momentos com seus filhos despertaram sentimentos múltiplos de surpresa, estranhamento:

E quando o Pedro nasceu foi uma sucessão de notícias não tão satisfatórias, porque pra mim já foi chocante meu filho nascer e eu nem ver a cara, ele não ficou em ventilação mecânica, nem foi de oxigênio pro berçário, mas eu nem pude ver, nem pegar foi muito chocante pra mim. E depois não conseguir pegar meu filho, nem amamentar, nem dar banho, nem trocar fralda nem nada (Daniela). 
Júlia nasceu bem, a princípio, sem nenhum problema aparente, com dois meses e vinte e poucos dias... foi aí que a gente descobriu o amareláo. Nasceu normal, APGAR 10, gravidez perfeita, fiz amniocentese, porque devido à idade, engravidei aos 44 anos, um filho de dezenove. Às vezes você fica receosa, e toma todos os cuidados (Helena).

Todo o processo de cuidado que irá se construir a partir desses primeiros momentos em que muito do que se espera ao se tornar mãe precisa ser desconstruído será marcado pelo o que foi denominado de paradoxo central (NELSON, 2002), isto é, sempre haverá tensão entre aceitação e negação da condição da criança, e este paradoxo é essencial para que essa relação mãe-filho possa se construir. Ao mesmo tempo que a mãe aceita e reconhece a condição de seu filho, o espaço para a esperança e otimismo em relação ao futuro se mantém.

Assim, esse lugar paradoxal que as crianças ocupam se apresenta não como um resquício de negação e sim como uma renegociação entre o que se imaginou e a criança nascida crônica. Essa renegociação exige um investimento enorme por parte das mães, ao falar sobre a esperança em novos tratamentos, terapias, até mesmo em células-tronco. A presença de esperança e otimismo dialoga com o lugar da diferença ocupado por seus filhos, em uma luta por reconhecimento de seus direitos.

Paez e Moreira (2016) exploram essa dimensão de uma corporalidade diferente que desafia o olhar materno sobre um filho nascido com uma condição crônica complexa, com muitas dependências tecnológicas. As autoras destacam que, ao desafiar o esperado sobre o que seria um corpo de criança apto a sobreviver, as interpretaçóes das mães permitem a atribuição de outros significados e intencionalidades. Esse processo produz intersubjetividade e permite o reconhecimento do filho como possível. Segundo esse artigo, aparatos tecnológicos e cuidados especiais exigidos e vistos como necessários precisam ser encarados como elementos a serem incorporados na rotina de cuidado, a fim de evitar distanciamento e um sentimento de exclusão por parte das mães. Faz-se necessário ainda transcender o utilitarismo das práticas baseadas num "treinamento" dos cuidados, como se treinar pudesse evitar as tensôes que as emoçôes promovem no contato com o cotidiano.

\section{Apoios e redes sociais}

$\mathrm{O}$ adoecimento crônico pode desencadear rupturas com as regras normais de reciprocidade e apoio mútuo (BURY, 1982). A internação prolongada de uma criança exige que a relação dos pais e da família se modifique em relaçấo a ela e entre seus 
membros. Os rearranjos são muitos, e a intensidade que os cuidados demandam, mesmo quando as crianças estão internadas, é alta.

As mães entrevistadas tiveram dificuldade em localizar quem seriam os apoios para elas. Esta dificuldade é encontrada em outros estudos de mães que têm filhos com doenças de longa duração (NÓBREGA et al., 2012; WEGNER PEDRO, 2010). Eles apontam que os homens, principalmente no período da hospitalização, são excluídos do cuidado e assim, quando voltam para a casa, o pai tem mais dificuldade de assumir as tarefas em relação a seus filhos, o que deixa as mulheres ainda mais sobrecarregadas:

O apoio hoje é o pediatra dela, o meu apoio é o cirurgião, até mesmo pra mim, qualquer coisa, eu falo com ele quase que diariamente, ou pra dar bom dia, ou ele pergunta de Júlia; criou uma amizade. Ele acompanha a Júlia no curso, ele está no facebook, no whatsapp, qualquer coisa eu pergunto (Helena).

Embora as mães sejam reconhecidamente as principais cuidadoras das crianças, sendo identificadas como tais em muitos estudos (MOREIRA et al., 2017; GAVAZZA et al., 2008; SILVA et al., 2013; NÓBREGA et al., 2012; WEGNER, PEDRO, 2010), há um esforço para reconhecer os pais nas pesquisas e incluílos nos discursos sobre cuidado, problematizando esse papel de coadjuvante que assumem. As redes sociais e esse campo de virtualidades aproximam pessoas, sejam profissionais e pessoas a eles referidas, e outras que se identificam com "causas". A ideia de que para essas mães as grandes referências são os profissionais pode falar de um certo sentimento de isolamento nessa experiência de reconstruir uma vida comum, sem mediaçóes de cuidado especializado.

A figura do homem é historicamente compreendida como secundária em relação ao cuidado e educação dos filhos, ocupando uma posição distante como provedor financeiro, acentuando ainda mais a diferença hierárquica entre ele e sua mulher (SILVA, 2010).

Em uma sociedade patriarcal como a brasileira, esse papel ainda é ocupado, embora tenha sofrido grandes modificaçôes. Alguns estudos (SILVA, 2010; NÓBREGA et al., 2012) mostram que o adoecimento do filho faz com que o pai busque estar mais presente, mesmo que ainda seja num papel de suporte à mãe. Fato é que novas configuraçôes familiares estão se estabelecendo, abrindo espaço para que pais possam compartilhar equanimemente os cuidados de seus filhos. Swallow et al. (2011) observam que é comum aos pais e mães desenvolverem habilidades 
para manter seus filhos com condiçóes crônicas em procedimentos e tratamentos. No entanto, os pais assumem o papel de "protetores" e se preocuparam mais com a saúde e o bem-estar de longo prazo, enquanto as máes se preocupavam mais com os problemas clínicos atuais, mantendo relacionamentos com os profissionais.

A sobrecarga gerada pelo cuidado complexo acaba por restringir a família à rede familiar mais próxima (WEGNER, PEDRO, 2010). Ainda assim, relaçôes de solidariedade, que estão para além da consanguinidade, são basicamente formadas por mulheres (NEVES et al., 2013). Essa rede se forma através dos conhecimentos e relaçóes de proximidade e afinidade com outras mulheres que também frequentam serviços de saúde com suas crianças adoecidas cronicamente. E podemos reconhecê-la como um elemento de uma base de apoio espontânea ou informal firmada no afeto.

Locais e serviços públicos de atenção à saúde próximos ao lugar onde essas crianças vivem são escassos. Dessa maneira, muitas delas continuam referenciadas ao ambulatório do serviço onde ficaram internadas e não têm muitas possibilidades de ocupar outros espaços que ofereçam atenção integral a elas. Por isso, a rede social das crianças e, consequentemente, das mães acaba ficando muito restrita ao espaço institucional e ao familiar nuclear. Ocupar espaços públicos como praças, escola e até mesmo a igreja se torna um desafio:

No dia que saí sozinha com eles dois [Para levá-los ao parquinho que fica no próprio condomínio onde moram] eu chorei, porque Pedrinho quis ficar no colo. Aí tive que pedir pra uma pessoa segurar o bebê pra mim e dar um pouco de colo pro Pedrinho e falar: Pedrinho, mamãe não pode ficar com você no colo. Porque ele náo aceita, ele fica agressivo se joga no chão. Aí eu liguei pro Pedro e falei pra ele me buscar pelo amor de Deus (Daniela).

Por mais que essas mulheres tenham algum tipo de possibilidade de rede, elas muitas vezes não conseguem as tecer, por se sentirem como principais e únicas pessoas capazes de cuidar de seus filhos. Elas acreditam que apenas elas estão habilitadas para melhor gerir a saúde de seus filhos, mantendo-os estáveis. Assim, confiar em outras pessoas e outros espaços para que seus filhos possam estar passa a ser muito difícil e muitas vezes essa devoção incondicional ao cuidado é reforçada pelos profissionais de saúde, que afirmam que o melhor para a criança é mesmo ficar em casa sob os cuidados da mãe, sem pensar nas implicações isso traz para toda a família.

Essas famílias passam por rearranjos grandes ao ter um filho com doenças de longa duração. Muitas vezes, esses são intensos e reorganizam suas vidas de maneira 
extrema, impondo a essas mulheres que criem novas normas para continuar levando suas vidas, que se tornam completamente diferentes do imaginado.

\section{Considerações finais}

A ida para casa de uma criança que passou um longo período internada, processo que denominamos desospitalização, é celebrada pela família e pelos profissionais, mas também é geradora de ansiedade. Por isso, mais que oferecer um "treinamento aos pais", é preciso trabalhar elementos de ordem emocional, vinculados aos sentimentos de segurança e insegurança, que pode vir a representar o diálogo hospital/ casa. Da mesma forma, as exigências clínicas podem fazer da casa um ambiente desafiador, tendo que ser transformada para receber a criança, mobilizando recursos materiais nem sempre disponíveis.

A casa, lugar do íntimo, da privacidade, é devassada e se torna o lugar da dúvida, do incerto. Ao mesmo tempo, há um cuidado profissional que se estende a esse território, tornando-o permeável ao discurso técnico, com barreiras fluidas que dificultam a autonomia da família no gerenciamento da rotina. Uma criança que passou por longas internaçóes, caracterizada como uma criança crônica complexa, com dependência tecnológica, quase que autoriza que serviços de atenção domiciliar, internação domiciliar e visitas técnicas se tornem comuns e rotineiros. $\mathrm{O}$ que vai acontecer com essa criança estando em casa? $\mathrm{O}$ discurso do risco toma força e às mães cabe gerenciá-lo com ou sem apoio, evocando o saber que desenvolveram durante os cuidados ainda no hospital, reconhecendo, ao mesmo tempo, que cuidar no hospital é cuidar cercada de "seguranças", da possibilidade de ter a quem recorrer. Enquanto ir para e cuidar em casa significa manejar a incerteza, o medo, a instabilidade, as memórias, as cobranças.

Foi através dos encontros e desencontros com as mães que pudemos observar o quanto assumir a função de cuidadoras de crianças com doenças de longa duração tem impacto na vida dessas mulheres ao voltarem para casa.

Entretanto, não podemos nos abster de questionar por que até hoje, mesmo com tantas discussóes sobre parentalidade, os pais não assumem, na maioria das vezes, o lugar de protagonistas no cuidado de seus filhos ao lado das mulheres. É importante questionar o quanto o próprio discurso do profissional de saúde náo corrobora os discursos antigos e exclui, pouco a pouco, o pai desse cuidado mais proeminente. 
Ao evocar memórias e reconstruir o percurso da experiência recuperada nas narrativas, mais do que falar sobre o processo de adoecimento de seus filhos, as mães encontraram um espaço para falar sobre elas. Sobre suas experiências como mães e mulheres, sobre mudanças, adaptaçôes e readaptaçôes em suas vidas, sobre seus projetos futuros.

Indicamos a importância de que outras pesquisas assumam e explorem o lugar dos homens nesse ambiente de cuidado complexo às crianças. Para os profissionais de saúde, há menos que treinar e mais o que negociar, em um cenário onde instituiçôes poderosas passam a disputar legitimidade sobre o direito de cuidar ou garantir saúde para essas crianças. O lugar das transiçóes do hospital para casa, desta para o ambulatório, da criança que cresce e se torna adolescente também deve se fazer presente como alvo de novos estudos. Se perguntar sobre como as escolas veem essas crianças, como lidam com elas e como se permitem flexíveis o suficiente para estar com elas também merece atenção. Vimos o quanto há de ressignificação na vida das mulheres e de seus filhos, que diante de tantos discursos de inviabilidades e complicaçôes conseguem todos os dias tecer novas possibilidades. ${ }^{1}$

\section{Referências}

ALVES, S. P.; BUENO, D. O perfil dos cuidadores de pacientes pediátricos com fibrose cística. Ciência \& Saúde Coletiva, v. 23 n. 5, p. 1451-1457, 2018.

BURY, M. Chronic illness as biographical disruption. Sociol Health Illn., v. 4, n. 2, p. 167-82, 1982. CANESQUI, A. M. Adoecimentos e sofrimentos de longa duração. São Paulo: Hucitec, 2013.

COHEN, E. et al. Children with medical complexity: an emerging population for clinical and research initiatives. Pediatrics, v. 127, n. 3, p. 529-538, 2011.

DAMATTA, R. A Casa e a Rua: espaço, cidadania e mulher no Brasil. Rio de Janeiro: Rocco, 1985. DINIZ, D. O que é deficiência. São Paulo: Editora Brasiliense, 2007. 96 p.

GAVAZZA, C. Z. et al. Utilização de serviços de reabilitação pelas crianças e adolescentes dependentes de tecnologia de um hospital materno-infantil no Rio de Janeiro, Brasil. Cad. Saúde Pública, v. 24, n. 5, p. 1103-1111, 2008.

HYDEN, L. C. Ilness and narrative. Sociology of Health \& Illness, v. 19, n. 1, p. 48-69, 1997.

LUPTON, D. It's a terrible thing when your children are sick: motherhood and homehealthcare work. Health Sociology Review, v. 22, n. 3, p. 234-242, 2013. 
MARCON, S. S. et al. Dificuldades enfrentadas pela família no cuidado a uma criança com doença crônica. Cienc Cuid Saúde, v. 6, n. 2, p. 411-419, 2007.

MOREIRA, M. C. N. et al. Recomendaçóes para uma linha de cuidados para crianças e adolescentes com condiçóes crônicas complexas de saúde. Cad. Saúde Pública, v. 33, n. 11, 2017. MOREIRA, M. C. N.; CUNHA, C. C.; MELlO, A. S. Conversando sobre as crianças e os adolescentes com condiçóes crônicas complexas na atenção primária. In: SANTOS, I.; ARABEllo, S.; GOldSTEIN, R. (Orgs.). (Re)Conhecendo Manguinhos: São Paulo: Hucitec, 2016.

MOREIRA, M. C. N.; GOMES, R.; SÁ, M. R. C. Doenças crônicas em crianças e adolescentes: uma revisão bibliográfica. Ciênc. Saúde Coletiva, v. 19, n. 7, p. 2083-2094, 2014.

MOREIRA, M. E. L.; GOLDANI, M. Z. A criança é o pai do homem: novos desafios para a área de saúde da criança. Ciênc. Saúde Coletiva, v. 15, n. 2, p. 321-327, 2010.

MOURA, E. C.et al. Complex chronic conditions in children and adolescents: hospitalizations in Brazil, 2013. Ciênc Saúde Coletiva, v. 22, n. 8, p. 2727-34. 2017.

NELSON, A. M. A metasynthesis: mothering other-than-normal children. Qual Health Res., v. 12, n. 4, p. 515-530, 2002.

NEVES, E. T. et al. A. A rede social de cuidados de uma criança com necessidade especial de saúde. Rev. Eletr. Enf., v. 15, n. 2, p. 533-540, 2013.

NEWACHECK, P. W.; KIM, S. E. A national profile of health care utilization and expenditures for children with special health care needs. Arch Pediatr Adolesc Med., v. 159, n. 4, p. 531-540, 2005.

NÓBREGA, V. M. et al. Imposiçóes e conflitos no cotidiano das famílias de crianças com doença crônica. Esc. Anna Nery, v. 16, n. 4, p. 781-788, 2012.

PAEZ, A.; MOREIRA, M. C. N. Physis, v. 26, n. 3, p. 1053-1072, 2016.

PINTO, J. P.; RIBEIRO, C. A.; PETTENGILL, M. A. M. O processo de recuperação da criança após a alta hospitalar: revisão integrativa. Acta Paul. Enferm, v. 23, n. 6, p. 837-842, 2010.

POLLAK, M. Memória, esquecimento, silêncio. Estudos históricos, v. 2, n. 3, p. 3-15, 1989.

SILVA, C. A. M. Necessidades dos pais de recém-nascidos prematuros no pós-alta clínica: Exercício de uma parentalidade autónoma. Porto, Portugal: Instituto de Ciências Biomédicas Abel Salazar, 2010.

SILVA, L. M. L.; MELO, M. C. B.; PEDROSA, A. D. O. M. A vivência do pai diante do câncer infantil. Psicol. Estud., v. 18, n. 3, p. 541-550, 2013.

SMITH, J.; CHEATER, F.; BEKKER, J. Parents' experiences of living with a child with a longterm condition. Health Expectations, v. 18, p. 452-474, 2013. 
SWALLOW, V. et al. A. Fathers and mothers developing skills in managing children's longterm medical conditions: how do their qualitative accounts compare?. Child: Care, Health and Development, v. 37, n. 4, p. 512-23, 2011.

WEGNER, W.; PEDRO, E. N. R. Os múltiplos papéis sociais de mulheres cuidadoras-leigas de crianças hospitalizadas. Rev Gaúcha Enferm, v. 31, n. 2, p. 335-42, 2010.

\section{Nota}

${ }^{1}$ B. S. M. de Castro realizou a pesquisa, análise de resultados e redigiu o artigo. M. C. N. Moreira supervisionou a realização da pesquisa, análise de resultados, redigiu e revisou a versão final do artigo. 


\section{Abstract}

(Re)cognizing their houses: narratives about de-hospitalization of children with long-term diseases

Our focus are the narratives of relatives of children with long-term conditions on the process of dehospitalization experienced by them, privileging the daily spaces of two families. Women continue to be the primary caretakers of children, and feel overwhelmed, unable to identify supports and support networks. The process of going home is challenging, requiring mothers to re-signify their lives after a long hospital stay. Children spend most of their time at home. Other community spaces that are in addition to the health services are still very scarce and almost not available. Rather than offering "parent training", emotional elements must be worked on, linked to the feelings of security and insecurity that may represent the hospital / home dialogue.

> Keywords: children; family; de-hospitalization; long-term condition; narrative. 